Artigo

\title{
El uso motivado del lenguaje: escritura y oralidad en los rituales de toma de posesión. El caso de Hispanoamérica colonial $^{1}$
}

\author{
Silvina Smietniansky \\ Consejo Nacional de Investigaciones Cientificas y Técnicas/Universidad Nacional de Quilmes, Buenos \\ Aires, Argentina \\ silvismiet@gmail.com
}

RESUMEN: La toma de posesión define una instancia de transformación en que pronunciamientos verbales, acciones rituales y textos escritos se combinan para producir y legitimar la concesión de un cargo o el traspaso de un bien, instituyendo un nuevo status en el sujeto protagonista. Este artículo propone una aproximación etnográfica al estudio de la dimensión performativa del lenguaje y los usos de la oralidad y la escritura en esos contextos rituales, en vista de comprender en qué reside la eficacia de dicha práctica. A partir de documentación elaborada en el marco de instituciones de gobierno en Hispanoamérica colonial, se examinan tres casos de tomas de posesión sobre objetos diferentes: un oficio público, una porción de tierras y una encomienda de indios. El abordaje de este problema incorpora una reflexión sobre la capacidad de las fuentes escritas para describir y crear ese mundo social al cual pretendemos aproximarnos.

PALABRAS-CLAVE: toma de posesión, lenguaje, escritura, ritual, Hispanoamérica colonial. 
Por mucho tiempo los antropólogos vieron en los rituales un criterio más para distinguir "sociedades primitivas" de "sociedades modernas". Si la magia y el ritual quedaban al lado de las primeras, la ciencia y el pensamiento empírico y racional definían a las segundas. Esa dicotomía ya no es válida desde el momento en que se reconoce que todas las sociedades apelan a múltiples formas en su ordenamiento del mundo. El problema, como apunta Stanley Tambiah (1996), es investigar cómo y por qué en determinados contextos comunicativos los hombres convierten las relaciones de semejanza o de metonimia en relaciones de identidad o de participación, de forma que el (supuesto) valor arbitrario y convencional de los signos queda opacado frente a la identificación, o "relación motivada", entre el signo y su referente. Este problema no es otro que el del carácter performativo del lenguaje, que nos obliga como enseñaron los mismos trobriandeses a Malinowski (1930) - a estudiarlo en términos de una forma de acción social y en el contexto de situación donde el sentido de los enunciados se hace comprensible. Una aproximación focalizada en el valor referencial debe por tanto ir de la mano con un abordaje que contemple su función pragmática (Silverstein, 1997 [1963]).

Atender al contexto cultural en que el lenguaje se inscribe impone a su vez considerar que no todas las sociedades apelan de la misma forma a los mismos recursos. La vuelta a casa de la antropología de cara a un mundo donde la escritura ocupa un lugar central en los modos de interacción social obligó a reflexionar sobre la producción de textos escritos y sobre la misma práctica de escribir (Barton y Papen, 2010). De igual forma que en el caso de los rituales y el discurso oral, la escritura también se ofrece a un análisis no restringido a su función referencial y que contemple de qué modo el acto de escribir y la fabricación de un objeto que es el texto reviste significación más allá del contenido del mensaje que pretende comunicar (Fraenkel, 2010).

Cuando volvemos la mirada sobre las antiguas colonias americanas de la Monarquía hispana, la generalidad de esas problemáticas se particulariza. En el contexto de una población en su mayoría analfabeta, donde los rituales operaban con vitalidad en el regimiento y la construcción del mundo social, la escritura marcaba con su presencia diversos aspectos de la interacción entre los individuos, además de definir una arena de comunicación y negociación entre las autoridades de un orden político policéntrico y signado por las grandes distancias. Entre esos miles de documentos que reposan hoy en los archivos históricos, se descubre una práctica recurrente, que reviste el carácter de un ritual y que los protagonistas de ese mundo históricamente distante tuvieron mucho cuidado en reproducir por escrito: se trata de la toma de posesión. 
SILVINA SMIETNIANSKY. EL USO MOTIVADO DEL LENGUAJE: ESCRITURA Y ORALIDAD EN LOS RITUALES ...

La idea de tomar posesión de algo no nos es ajena. En Argentina el nuevo presidente toma posesión de su cargo en un ritual que incluye la entrega del bastón presidencial, la proclama de un juramento y la elaboración de un acta. En EEUU el presidente electo takes the Oath of Office, mientras en Brasil cuando un funcionario de gobierno se inicia en el ejercicio de un nuevo cargo procede a tomarposse. Esas tomas de posesión no parecen tan alejadas de aquellas asentadas en las fuentes coloniales. Patricia Seed (1995) compara las diferentes formas en que los conquistadores europeos "tomaban posesión” de los nuevos territorios y creaban derechos de dominio, y aborda la figura del requerimiento para el caso español. La fundación de ciudades hispanas también comportaba un ritual de toma de posesión de las tierras conquistadas y de imposición de un nuevo orden (Boixadós, 1994). Otros trabajos dan cuenta del modo ritual a través del cual los virreyes tomaban posesión de las jurisdicciones que venían a gobernar, lo que suponía tomar posesión del cargo para el cual habían sido designados (Cañeque, 2004; Osorio, 2004; Ortemberg, 2014). El ritual de entrada al vasallaje que informaba esas prácticas también involucraba, entre sus fases, la toma de posesión del feudo (Le Goff, 1983 [1978]).

La toma de posesión comporta una práctica generalizada que puede rastrearse en contextos temporales e institucionales diversos y que define una instancia de transformación. Es un acto en que pronunciamientos verbales, acciones rituales y textos escritos se combinan para producir y legitimar la concesión de un cargo o el traspaso de un bien, instituyendo un nuevo status en el sujeto protagonista. El enfoque que guía nuestro análisis sobre las tomas de posesión recupera y dialoga con los aportes de Tambiah en el estudio de los rituales, cuya pertinencia y riqueza para el caso que nos ocupa se vislumbra, en principio, en dos aspectos. Por un lado, las tomas de posesión revisten una serie de características que admiten ser examinadas como rituales, premisa que, según iremos viendo, conduce la atención hacia el modo secuencial en que se desarrollan las operaciones simbólicas puestas en juego y los efectos que producen. Por otro lado, al analizar el carácter performativo de los rituales y provisto de las herramientas de la lingüística y la filosofía del lenguaje, Tambiah resitúa en este campo tradicional de la antropología las críticas efectuadas al modelo saussureano. La noción de performatividad alude, en primer lugar, a la perspectiva pragmática de John L. Austin (1975 [1955]), desde la cual los actos performativos son aquellos que producen la realidad que describen; en segundo lugar, a los múltiples canales de comunicación que se despliegan y que contribuyen a intensificar los sentidos transmitidos en el ritual; y, finalmente, al carácter indexical de los signos, según fuera formulado por Charles Peirce (1955) en su teoría de los signos - la figura modélica es la del índice, un tipo de signo 
que es afectado, motivado, por el objeto que representa. De esta manera, inspirados por las ideas de Tambiah en diálogo con estas fuentes teóricas, descubrimos en las tomas de posesión un terreno propicio para abordar el problema de la performatividad del lenguaje y, en particular, los usos de la oralidad y la escritura.

Este artículo propone avanzar etnográficamente en esa tarea a través de un análisis de documentación elaborada en el marco de instituciones del gobierno hispano colonial. Se examinarán tres casos en que tuvo lugar una toma de posesión sobre objetos diferentes: un cargo en el gobierno local, una porción de tierras y una encomienda de indios ${ }^{2}$. El corpus que delimita nuestro universo etnográfico se compone de actas capitulares, expedientes jurídicos, mercedes de tierras y de encomiendas de indios, testamentos y contratos de compraventa; todos ellos producidos en los siglos XVII y XVIII en el contexto de la gobernación del Tucumán ${ }^{3}$. Vender, testar o hacer una merced eran actos en que el bien se cedía y que se realizaban a través de la producción de un registro escrito, mientras que la toma de posesión con un énfasis en la oralidad y la acción ritual comprendía la instancia final en que el mismo se recibía, en que se tomaba posesión de ese objeto.

Tratándose de una investigación basada en materiales escritos, este artículo busca también reflexionar sobre cómo construimos y empleamos las fuentes históricas que definen nuestro campo etnográfico. Por el momento cabe apuntar que el tratamiento que damos a los documentos exhibe un carácter doble. Por un lado, ellos constituyen el medio de que disponemos para reconstruir las acciones rituales pasadas y son, por tanto, tratados como indicios para acceder a situaciones ya concluidas. Por otro lado, su producción, circulación y permanencia aportaron a construir ese mundo al cual pretendemos ahora aproximarnos, es decir, operaron sobre una realidad que pretendían objetivamente describir. Este segundo aspecto repara en los valores, creencias y significados asociados a la escritura, entendida ésta como una práctica social y cultural cuyo análisis requiere atender al contexto procesual en que la misma se inscribe (Barton y Papen, 2010; Fraenkel, 2010). Como apunta Ann Laura Stoler (2002: 89), "we are no longer studying things, but the making of them", y los archivos coloniales no son ajenos a ese impulso. En diálogo con estas ideas que delinean una aproximación etnográfica al estudio de la escritura y los materiales de archivo, el corpus documental que examina este artículo es considerado, al mismo tiempo, instrumento y objeto de investigación. A través de esa doble condición discurre el ejercicio de análisis y reflexión. 


\section{Toma de posesión de cargos públicos}

Bajo el modelo de colonización hispana, cada ciudad estaba gobernada por su propio cabildo encargado de administrar la vida social, política y económica de la comunidad local. El acceso al cabildo, sólo habilitado para quienes revestían en la categoría de vecino ${ }^{4}$, podía lograrse por dos vías (dependiendo del cargo): a través de la elección anual de alcaldes o comprando un oficio en un remate público.

Las elecciones capitulares se realizaban al final de cada año en las casas del cabildo y revestían, como todas las sesiones del cuerpo, un carácter privado. Se elegían dos alcaldes ordinarios y dos de la Santa Hermandad. Los primeros eran la cabeza del cabildo (sin ellos el cuerpo no podía reunirse) y administraban la justicia en primera instancia, mientras que los segundos instruían la justicia en la campaña y tenían voz pero no voto. El proceso electoral quedaba asentado en los libros del cabildo, donde se consignaban los votos enunciados oralmente por cada miembro. Votaban los funcionarios con derecho a voto y los alcaldes ordinarios salientes.

El 30 de diciembre de 1656 el teniente general de la gobernación de Tucumán se dirigió al cabildo de la ciudad de Córdoba advirtiendo que las elecciones se desarrollasen “con toda paz y quietud", que los electos sean "personas capaces de bu [ [buena] conciencia y que descarguen la de su mag ${ }^{\mathrm{d}}$ [Majestad]" y que cumplan en administrar justicia con igualdad entre las partes ${ }^{5}$. Con algunas variaciones en esas fórmulas, el proceso electoral se iniciaba con la voz del gobernador (en la ciudad en que residía) o la de su teniente recordando los valores que debían guiar el obrar del cuerpo. En las elecciones de 1656, por ejemplo, también fueron leídas las ordenanzas establecidas por el fundador de la ciudad relativas al modo en que debían sustanciarse.

El 31 de diciembre se llevó a cabo la votación y el $1^{\circ}$ de enero tomaron posesión de sus cargos los nuevos alcaldes. El "rito cívico" se inició con un solemne carácter religioso, invocando al Santísimo Sacramento y a la Virgen María. Siguiendo el orden jerárquico que establecía la estructura corporativa del cabildo y que tenía al alcalde ordinario de primer voto en la cabeza, cada uno de los miembros habilitados enunció oralmente los nombres de los individuos a quien otorgaba sus votos. El alcalde provincial de la Santa Hermandad, alegando enfermedad, se encontraba ausente y, en su lugar, profirió sus votos el escribano. Éste manifestó que esa decisión que estaba contenida en un sobre cerrado (y que entonces estaba leyendo) era la misma que oralmente había declarado el funcionario en su casa. 
Una vez concluida la votación, los autos fueron remitidos al gobernador, que debía confirmar los resultados del proceso electoral. Contando con esta aprobación fijada por escrito, los electos hicieron entrega del derecho de media anata - tasa impositiva que debía pagarse al ingresar en un cargo público - al tesorero y prosiguieron con el acostumbrado “juramento de buen uso de sus oficios".

El juramento se iniciaba y conclúa invocando a Dios, quien mediaba en el compromiso que los alcaldes electos estaban estableciendo con vistas a sus nuevas funciones. Los individuos ofrecían por intermedio de la palabra oral la promesa de su accionar futuro; el mismo acto de enunciar ciertas fórmulas en ese contexto ritual instituía ese pacto: juraron usar "bien y fielmente" los cargos para los que habían sido electos, resguardar "el bien de la república", administrar justicia con igualdad entre las partes, respetar las cédulas y ordenanzas del rey y cuidar de los indios, viudas, huérfanos y pobres ${ }^{6}$. El carácter religioso de la apertura y del cierre del juramento pareciera operar transfiriendo el acervo sagrado propio de la divinidad a los compromisos que los funcionarios asumían en el regimiento del gobierno local, al tiempo de reafirmar la imbricación entre política y religión.

Una vez que el teniente recibe el juramento, como parte de ese intercambio procedió a entregarles a los nuevos miembros del cabildo la vara de justicia, una suerte de bastón que estaba terminado en cruz o que la tenía grabada sobre el casquillo. Había diferentes tamaños de varas en correspondencia con los cargos de gobierno, unas eran más altas, alrededor de un metro y cuarenta, para los ministros de justicia, y otras más cortas, destinadas a funcionarios de rango inferior (Bayle, 1952; Bridikhina, 2007). El uso de la vara otorgaba autoridad a sus portadores $-y$, con ello, el prestigio de ejercer un oficio público - y constituía un indicador a través del cual eran públicamente reconocidos en su función de jueces. Esta insignia de origen castellano implicaba la concepción de que el monarca era el titular supremo y originario de la justicia y que la delegaba - de hecho, entregaba la vara - a los magistrados que actuarían en su nombre. "Varas y alcaldes anduvieron siempre juntos", refiere Bayle (1952: 260). Metonímicamente, la vara designaba al oficio de su portador, entonces quitar la vara o asumir la vara connotaba, respectivamente, ser destituido del oficio o incorporarse en el ejercicio del mismo. Recibir la vara señalaba e instituía la toma de posesión del cargo.

Aunque en el contexto del juramento examinado no se mencionó explícitamente la fórmula señal de posesión o acto de posesión, que indagaremos en las tomas de posesión de tierras y encomiendas, sí quedó registrado en otros casos similares. Por ejemplo, cuando en 1764 en el marco del juicio de residencia al gobernador Tineo se designó al Maestre de Campo 
don Esteban de Montenegro como juez subdelegado para la ciudad de Córdoba. Luego de prestar juramento, en el expediente consta que "en señal de posesión en nombre del rey [el alférez real] le hizo entrega de una vara alta de justicia...”’

Como referimos, la compra de un oficio era otra de las vías de acceso al cabildo. Y ese proceso también incluía el acto de toma de posesión: el comprador sólo se constituía en legítimo poseedor del cargo una vez que era recibido por el cabildo con la correspondiente proclama del juramento y entrega de la vara. A diferencia de las elecciones, que tenían una fecha estipulada en el calendario anual, los cargos eran puestos en venta cuando una plaza quedaba vacante o cuando una nueva se abría. Con motivo de los problemas financieros que en el siglo XVII enfrentaba la monarquía hispana, muchos de los oficios capitulares se fueron transformando en oficios vendibles. Los remates se llevaban a cabo en la plaza pública de la ciudad por voz de un pregonero que enunciaba oralmente - "en altas e inteligibles voces" - cuál era el cargo en venta, las competencias y el precio de mismo. Era usual la proclama de 30 pregones, uno por día, en cuyo desarrollo, como es acostumbrado en los remates, los individuos interesados podían acrecentar el precio de la vara a través de enunciar oralmente el monto mayor propuesto.

De igual forma que en el caso de las elecciones, los textos elaborados en los remates describían las acciones que en su transcurso se iban desarrollando. El estilo de la escritura parecería pretender comunicar de modo objetivo lo sucedido en cada pregón, allí se registraba: la fecha y el lugar, la autoridad competente que validaba el evento, el nombre y condición social del pregonero, el contenido del texto enunciado y la aparición de algún nuevo ponedor con el aumento del precio propuesto, en caso de que lo hubiera. Una vez que se publicaban todos los pregones y se identificaba al mayorponedor, el pregonero concluía oralmente la venta del cargo: "a la una, a las dos, a las tres, que buena pro le haga con que por lo que a mi toca se hizo el dicho remate en el dicho teniente..." de administrar el remate certificó qué sujeto había efectivamente ofrecido la propuesta más cuantiosa. Se estipulaba entonces la modalidad de pago (en general, en varias parcelas), el comprador sufragaba la tasa de media anata y se dirigía al cabildo con el testimonio escrito del remate para proceder a tomar posesión del cargo.

Oralidad y escritura asumían lugares diferentes a lo largo del proceso. El remate y venta del oficio revestían un carácter oral: la puja era oral y la venta a favor del mayor ponedor concluía con la voz del pregonero - avalado con la autoridad presente designada. La escritura operaba como un testimonio de que el remate había sido correctamente sustanciado y la venta, por tanto, legítima. Es decir, mientras se enfatizaba, por un lado, la función performativa del 
SILVINA SMIETNIANSKY. EL USO MOTIVADO DEL LENGUAJE: ESCRITURA Y ORALIDAD EN LOS RITUALES ...

ritual y del registro oral, por otro lado se adjudicaba a la escritura un valor referencial. Ahora bien, que el texto fuera presentado como signo de una realidad preexistente no quiere decir que no ayudara en sí mismo a construirla.

Si los rituales son eventos que la misma perspectiva nativa recorta como singulares o especiales (Tambiah, 1985; Peirano, 2001), el texto cuyo objetivo es relatar un ritual ofrece una perspectiva sobre cuáles son los elementos significativos de ese ritual que lo tornan eficaz. Lo que sugerimos es que el registro labrado en el remate al tiempo de relatar un evento - y permitirnos reconstruir algunos de sus trazos orales - operaba construyendo una definición sobre cómo debía efectuarse ese ritual y qué elementos le conferían legitimidad. Cuando hoy en día leemos una y otra vez relatos oficiales sobre remates, elecciones, tomas de posesión etc., y vemos que para cada caso se refieren más o menos las mismas acciones, imaginamos que así fueron típicamente sustanciados. El problema aquí no es la veracidad de ese evento, sino la capacidad del registro escrito para definir y fijar en qué consiste ese evento. Visto en estos términos, advertimos que el texto, lejos de ser un signo arbitrario, participaba de su propio referente (Tambiah, 1996).

La performatividad del auto del remate residía también en que, en tanto testimonio, tenía el poder para habilitar la toma de posesión del cargo vendido. Es decir, el texto por sí mismo no producía el acceso al cargo, pero lo posibilitaba a modo de un canal que conducía a los actores desde el remate en la plaza pública hasta el recibimiento y jura en el interior del cabildo. El acto de entrega de un cargo y la toma de posesión del mismo se producían en dos instancias de carácter ritual que se ligaban a través de un registro escrito.

Vemos entonces que la oralidad revestía un papel preponderante tanto en las elecciones como en los remates. Ambas eran ocasiones en que se concedía un oficio público, pero el sujeto sólo podría acceder al ejercicio del mismo al ser recibido por el cabildo y sustanciar el correspondiente ritual de toma de posesión. Incluso, cuando en los dichos se hacía referencia al período en que un individuo había ejercido un determinado puesto en la administración de gobierno, se señalaba la toma de posesión del cargo como el punto de inicio.

\section{Toma de posesión de tierras}

La colonización de los territorios y el establecimiento de las ciudades que luego constituirían la provincia del Tucumán se llevó a cabo en función de los recursos que la región albergaba. 
En la perspectiva de los conquistadores la fuente de riqueza material más importante residía en su población indígena y en la disponibilidad de gran cantidad de tierras aptas para la explotación agrícola y ganadera. Los recién llegados recibieron encomiendas de indios y mercedes de tierras en remuneración por los servicios prestados. En realidad, los pedidos de retribución de esta clase y su entrega no concluyeron luego de la primera etapa de conquista; persistieron durante los siglos XVII y XVIII en el marco de las luchas entabladas en la frontera interna, los valles Calchaquíes, y en la frontera oriental con el Chaco. Pacificada la primera de ellas, el siglo XVIII se inició con el cambio hacia una estrategia ofensiva sobre los habitantes del Chaco. Los españoles impulsaron continuas campañas militares adentrándose en las tierras de los naturales hasta lograr su pleno dominio a mediados de esa centuria.

En ese contexto de avanzada militar, el teniente Diego Dávalos elevó al gobernador Urízar y Arespacochaga (1707-1724) una petición para que se le entregara una merced de tierras como remuneración por los servicios prestados al rey. En ella refiere que "ha servido a su Majestad en las entradas generales, y corredurías" en la frontera chaqueña y que él mismo ha solventado esas participaciones. Alegando también la necesidad de mantener a su familia - manifestaba estar casado y con hijos -, suplicaba al gobernador que "se sirva de hacer merced en nombre de su Majestad de unas tierras" ubicadas en valle de Normenta9. Bajo esas fórmulas típicas, las peticiones de mercedes de tierras incluían las acciones pasadas del solicitante o sus antecesores, la obligación de sustentar una familia, la condición de vecindad o su reconocimiento como un hombre honrado, entre otros aspectos (Mariliuz Urquijo, 1978). En América, de igual forma que en la reconquista española, las nuevas tierras conquistadas pertenecían al rey y éste por gracia o favor real las concedía a los participantes de las empresas colonizadoras. Las mercedes de tierras y de encomiendas de indios canalizaban tales entregas y señalaban el pacto reciprocitario entre el rey y sus vasallos, y los términos "merced" y "servicio" simbolizaban esas obligaciones mutuas concebidas en relación con un modelo de sociedad patrimonial (Elliot, 1990).

La prestación y la contraprestación no se realizaban de forma inmediata. Acorde a un tipo de vínculo reciprocitario que debe mostrarse despojado de intereses privados y motivado por la voluntad, la moral y la generosidad (Mauss, 2009 [1925]), Dávalos primero facilitó sus servicios en la guerra y luego solicitó la merced. Seguramente esperaba la acostumbrada gratificación, pero ésta no estaba a priori garantizada. Al otorgar mercedes, títulos, beneficios etc., el rey realizaba actos de "gracia" - a imagen de Dios - que no se consideraban en sí mismos obligatorios ni se orientaban a satisfacer y reproducir un orden preexistente, aunque se entendía que contribuían al ordenamiento y equilibrio del cuerpo social (Agüero, 2007). 
Dos años después de efectuada la petición, también por vía escrita el gobernador, en nombre del rey, otorgó su respuesta favorable atendiendo a las acciones pasadas, presentes y futuras. Reconocía en Dávalos un "benemérito de esta Guerra”, señalaba los méritos pasados y los servicios que aún estaba presentando en "la Guerra viva de estas fronteras" y también preveía el derecho futuro que tendrían sus hijos y sus herederos a usufructuar esas tierras ${ }^{10}$. El auto obraba como título de la propiedad y, una vez que Dávalos sufragó el impuesto correspondiente, un alcalde de la Santa Hermandad comisionado para la ocasión procedió a ejecutar la toma de posesión de las tierras. El acto sustanciado en el Valle de Normenta el 21 de septiembre de 1720 quedó registrado en el auto que el funcionario labró en primera persona. Como en todo documento de esta clase, primero se indica la fecha y el lugar en que se llevó a cabo y los protagonistas. Luego consta que Dávalos presentó el título con la correspondiente certificación del pago del gravamen y "pidió que en su virtud le diese la posesión de las tierras en que me hallaba"11. No se indica que la merced haya sido leída; en el relato es tratada como un objeto que señalaba la legitimidad del acto que en breve habría de sustanciarse.

“Cogí por las manos al dicho Dávalos, y le di posesión Real actual, Corporal, jure domini, vel quasi" suscribió el alcalde en el auto de toma de posesión. Estas formas de expresión que hundían sus raíces en el derecho romano definían el carácter material del bien que era objeto de la toma, el poder físico que se otorgaba sobre ese bien y también los derechos útiles que incluía el usufructo de las tierras (Beceiro Pita, 1994) ${ }^{12}$. El gesto manual combinado con la enunciación de esas fórmulas que describían la acción que se estaba desarrollando exponía de modo ritualmente económico el objetivo del ritual. Las manos de Dávalos revestían un carácter metonímico: tal cual lo testimonió el alcalde, a quien él tomaba era "al dicho Dávalos" y esto lo hacía "por las manos". Esta acción expresaba la toma de posesión de las tierras que se estaba sustanciando a favor de Dávalos; pero más aún, era un componente que dentro de dicho acto contribuía a producir y legitimar la posesión - es decir, instituía a Dávalos como poseedor del inmueble y transformaba su status. En relación con ello debe notarse que análogamente se toma o se coge las manos de igual manera que se toma posesión de un bien: el alcalde (en nombre del rey) toma las manos de Dávalos y éste toma las tierras. Aunque, por otro lado, en cada caso los actores asumían los roles inversos: las manos eran entregadas por Dávalos y las cogía el alcalde (en nombre del rey), mientras las tierras eran cedidas por el rey y tomadas por Dávalos.

En ese sentido, a continuación, el texto describe que Dávalos tomó la posesión de las tierras "quieta y pacíficamente" sin que ninguna persona lo objetara: arrancar hierbas, mover 
de lugar piedras y echar a los presentes expresaban que desde entonces él era el propietario de esos terrenos, lo que devela la eficacia simbólica de las acciones sustanciadas previamente. En los testimonios de tomas de posesión esta clase de comportamientos en que la persona transitaba y operaba a su antojo sobre el espacio físico recibe dos denominaciones: señales de posesión y actos de posesión, que deben diferenciarse de toma de posesión. Éste último refiere a toda la secuencia de acciones que en el auto se inicia con la marcación de la fecha y el lugar y concluye con las firmas, mientras que señales y actos de posesión apuntan a ciertas acciones específicas desarrolladas en el marco de la toma de posesión.

Como también se registra en otros $\operatorname{casos}^{13}$, se produce una asimilación entre las expresiones señal (de posesión) y acto (de posesión), lo que podría sugerir que señalar en tanto simbolizar la posesión era al mismo tiempo producir esa acción (el acto de poseer un bien). Si esa interpretación es correcta, entonces se advierte que el carácter productivo del ritual se registra tanto en el plano de la acción como en el nivel de las categorías nativas (su uso y significado). Es decir, por un lado las acciones que señalaban el status de propietario eran también las que contribuían a producirlo - lo que implica una relación motivada entre el signo y su referente (Tambiah, 1996): hacer uso del espacio físico era una señal y un acto de poseer esas tierras ${ }^{14}$. Por otro lado, la sinonimia de los términos acto y señal sugiere que el sentido de actuar, de instituir, resultaba incorporado a la categoría de señal ${ }^{5}$.

Una vez realizados esos actos de posesión, vuelve a escena la producción de un registro escrito que marcaba el cierre de la toma de posesión y, en términos más amplios, del proceso de entrega legítima y efectiva del objeto de merced. Dávalos le solicitó al alcalde un testimonio que lo amparase en dicha toma y éste fundó la veracidad del mismo en virtud de haber visto toda la secuencia ritual. La visibilidad refuerza la importancia de la acción ritual: tomar posesión de las tierras implicaba mostrar esa posesión y el registro escrito daba efectiva cuenta de ello. Al comparar la toma de posesión con la solicitud y el auto de merced, se advierte que en los últimos dos casos la escritura era el canal a través del cual se realizaba un pedido y se concedía una retribución, mientras en el contexto de la toma de posesión la eficacia residía en el ritual (que hacía efectiva la posesión). Asimismo, la retórica del documento resultante acentuaba la función referencial del lenguaje y aportaba a construir ese texto como una descripción externa de la serie de acciones que se sucedían: "que todo lo referido pasó así según y como se lo expresa en esta diligencia” refiere el alcalde, quien con su firma y la de los testigos dotó de legitimidad y eficacia jurídica a ese relato.

A los pocos años la propiedad fue vendida. Al respecto importa señalar que la escritura 
de compraventa no fue un instrumento que por sí mismo otorgase la propiedad de las tierras. En el marco jurídico del derecho romano el convenio que establecía la compraventa generaba la obligación de hacer entrega del bien, pero el comprador se constituía en propietario una vez que se hubiere efectuado la entrega material de dicho objeto (Levaggi, 1982). Es decir, en nuestro caso el comprador debía tomar posesión de las tierras que Dávalos le había vendido. Ese proceso de compraventa, igual que en el caso de la merced, se inició con un documento escrito (el contrato), se efectivizó a través de una secuencia de acciones rituales (la toma de posesión) y concluyó con el auto que testimoniaba la toma de posesión. Éste último de ahí en más tenía eficacia jurídica para, junto con el contrato, amparar al nuevo propietario.

\section{Toma de posesión de encomiendas de indios}

La concesión de encomiendas de indios se fundaba en la misma lógica reciprocitaria que las mercedes de tierras. Sin embargo, a diferencia de España, donde tomar la posesión de un feudo implicaba la potestad sobre las tierras y su población, en América ambos dominios se conducían por carriles distintos. Las encomiendas de indios implicaban "la asignación de grupos de indios a colonos españoles escogidos (encomenderos) para recibir tributos y mano de obra" y en contraprestación los encomenderos debían cumplir con la evangelización y cuidados de los naturales a su cargo (Gibson, 1990: 161). La adjudicación de una encomienda de indios no conllevaba ningún título sobre las tierras ni tampoco otorgaba el ejercicio de jurisdicción; incluso, las encomiendas debían volver a la corona al fallecer su propietario, evitando así la perpetuidad de las mismas (perpetuación que procuraban los encomenderos) (Elliot, 1990; Mörner, 1990). La sucesión de las mismas revestía el carácter de privilegio que concedía el rey antes que de derecho formal y ordinario.

En 1614 el gobernador don Luis de Quiñones Osorio le concedió al capitán Lázaro de Villafañe, lugarteniente de gobernador en La Rioja, una encomienda de indios en el valle de Andalgalá ${ }^{16}$. Fundaba dicha entrega en los servicios que había prestado al rey tanto en España como en América y habilitaba su posesión por dos vidas, es decir, la de Villafañe y la de su sucesor. La encomienda fue usufructuada en segunda vida por uno de sus hijos y, ante su deceso (1632), don Isidro de Villafañe y Guzmán - otro hijo de Lázaro - presentó una solicitud para que se le concedieran dichos repartimientos de indios. Apelaba a los méritos de su abuelo, su padre y su hermano; y también señalaba el estado de pobreza en que había 
quedado luego de la muerte de éste último a manos de los indios. El gobernador Felipe de Albornoz le concedió ese pedido y en el auto de merced dejaba asentado los compromisos que contraía con él, con los indios encomendados y con el rey. Se encargaría de administrar el tributo indígena de acuerdo con las ordenanzas reales al tiempo de darles a los indios "buen tratamiento" y enseñarles la doctrina cristiana, respetando las "exenciones y preeminencias" propias de los caciques. Isidro quedaba también obligado a residir en la ciudad de La Rioja y a participar en las campañas militares o prestar contribuciones a las mismas ${ }^{17}$.

El 7 de septiembre de 1633 en La Rioja se llevó a cabo la toma de posesión bajo la conducción del capitán don García de Mercado y Reinoso, alcalde ordinario de dicha ciudad. Isidro de Villafañe y Guzmán presentó el título de encomienda otorgado por el gobernador y a continuación el alcalde le tomó el juramento de fidelidad, recordando los compromisos que asumía con el Rey. Isidro juró por Dios y realizó una señal de cruz con la mano derecha. Prometió servir y ser fiel al Rey y al gobernador, acudir en aquello que le fuere ordenado, establecer casa poblada en la ciudad, tener pertrechos, armas y caballo para la guerra y cumplir con las obligaciones que tenía en tanto vecino. Finalmente, “dijo que sí juro y prometo amén” y su firma junto con la del alcalde selló el auto ${ }^{18}$.

El juramento que proclamó Villafañe recuerda al juramento de fidelidad que Le Goff (1983 [1978]) señala como el segundo estadio del ritual vasallático, en el cual primaba el recurso de la palabra y se sustanciaba sobre la Biblia o alguna reliquia. Villafañe juraba fidelidad al rey y al gobernador, de igual manera que un vasallo lo hacía con su nuevo señor o éste con el rey. Sin embargo, a diferencia del ritual de vasallaje, en las entregas de encomiendas analizadas hasta ahora no registramos la inmixtio manuum, el gesto manual que sí aparece en las tomas de posesión de mercedes de tierras. Es decir, en la toma de posesión de la encomienda se sustanció el juramento de fidelidad, pero las manos de Villafañe no fueron envueltas entre las del alcalde; y, a la inversa, en las mercedes de tierras examinadas se practicó la imposición de manos, pero no el juramento de fidelidad.

A continuación, Villafañe le solicitó al alcalde tomar posesión de los indios; en respuesta, el funcionario hizo leer la merced concedida por el gobernador y luego le requirió a Villafañe que presentase indios a través de los cuales darle la posesión de la encomienda. Villafañe trajo un indio que, según el alguacil que ofició de intérprete, “dijo llamarse Miguel Turquinima natural del pueblo de Alongascut su padre y de Nogolma su madre" ${ }^{19}$. El alcalde confirmó que estaba comprendido en el título de encomienda y pasó a ejecutar las acciones acostumbradas: 
cogí de la mano al dicho indio y se lo entregué al dicho don Isidro Villafañe diciendo en éste doy a vuestra merced la posesión de estos indios y pueblos en voz y en nombre de todos ellos el cual la recibió de mi mano que en nombre de su Majestad le dije le daba la dicha posesión y el susodicho en señal de ella mandó al dicho Miguel que fuese a su casa a le servir haciendo otros actos y señales de posesión y de cómo la aprehendía de día claro en presencia de testigos y en la plaza pública y en concurso de gente y sin contradicción de persona alguna. ${ }^{20}$

El acto de tomar posesión de una encomienda de indios recuerda las acciones, los gestos y las palabras implicadas en las tomas de posesión de tierras. El alcalde fue comisionado por el gobernador y lo ejecutó en representación del rey. Se toma a un indio para, metonímicamente, indicar la toma de posesión sobre el conjunto de los naturales de dicha encomienda. Más aún, dirigirse al indio encomendado y darle una orden en "señal de posesión" manifestaba la nueva relación jerárquica de mando y obediencia que desde entonces quedaba instalada. Le Goff (1983 [1978]) refiere que en el ritual de entrada al vasallaje el desplazamiento del vasallo hacia el señor (hacia la iglesia o un castillo señorial donde tenía lugar el ritual) respondía a dos objetivos: situaba el ritual en un espacio que revestía un carácter simbólico y comenzaba a definir el vínculo jerárquico que se instituía entre el señor y su vasallo - destacando la deferencia que el vasallo, de status inferior, le debía al primero. Así como en las tomas de posesión de tierras el nuevo poseedor arrancaba hierbas o tiraba piedras, en este caso Villafañe enunciaba una orden que era inmediatamente cumplida por el indio. Ambas acciones, sea a través del gesto o de la palabra, develan su eficacia para instituir la posesión. La función performativa del lenguaje que se advierte en la toma de posesión de la encomienda refuerza la interpretación propuesta en el apartado anterior sobre la noción de señales de posesión, que señalaban pero que, al mismo tiempo, producían la posesión.

Con respecto al espacio en que tenía lugar la toma de posesión, mientras en el caso de los bienes inmuebles se hacía dentro de los límites de éstos, en el caso de las encomiendas se sustanciaba en la plaza pública de la ciudad lo que otorgaba un mayor alcance a la publicidad del evento. La claridad o luminosidad del día son aspectos que recurrentemente se destacan en el registro escrito de estos rituales de posesión, como si acaso esas propiedades se hubieran transferido por contagio al acto de intercambio que allí se estaba desarrollando, otorgando una mayor visibilidad (y pureza?) al mismo.

Finalmente, el auto se cierra con el escribano manifestando certificar y testimoniar 
SILVINA SMIETNIANSKY. EL USO MOTIVADO DEL LENGUAJE: ESCRITURA Y ORALIDAD EN LOS RITUALES ...

todo lo acontecido. Con la firma del alcalde se entendía que ese registro del pasado devenía en un documento dotado de eficacia jurídica que a futuro afirmaría la legítima autoridad de Villafañe como encomendero de ese repartimento. $\mathrm{Al}$ analizar la toma de posesión de cargos ya apuntamos el carácter performativo de la producción de esta clase de documentos, a pesar de que el tipo de retórica y las categorías utilizadas terminan por ofrecer un texto que se erige en una descripción objetiva de lo que estaba aconteciendo.

\section{Signos motivados, oralidad y escritura: sobre la mágica eficacia de tomar posesión}

La toma de posesión se transformaba en un registro escrito al tiempo en que se estaba desarrollando. En realidad, si advertimos que los autos labrados en primera persona por los funcionarios de gobierno eran escritos en tiempo pasado (cogí, se paseó, bizo señales de posesión etc.), debiéramos decir que inmediatamente luego de su celebración se volcaba a modo de relato. El ritual implicaba entonces una acción presente en que se estaba instituyendo el dominio sobre un cargo, un territorio o una encomienda, pero en el instante en que se fijaba por escrito se constituía en una acción consumada, pasada y claramente efectiva. Asimismo, la perspectiva de permanencia de ese registro escrito que podría dislocarse, manipularse, guardarse y exhibirse suponía un horizonte futuro en que ese texto operaría como resguardo de la eficacia conseguida en el ritual pasado. Podría decirse que en este caso la eficacia del ritual se trasladaba al documento. Aunque, por otro lado, la distinción analítica que marcamos entre el ritual y el texto no debe hacernos pasar por alto que ese registro escrito y la misma acción de su fabricación fueron componentes de la toma de posesión. El auto constituye al mismo tiempo un testimonio de lo acontecido y la fase conclusiva de ese proceso ritual. Dicho de otra forma, el documento y las autoridades encargadas de su elaboración eran partícipes del referente de esa descripción escrita. Tal vez allí resida nuestra dificultad por intentar deslindar el valor referencial y el aspecto performativo en un texto que pareciera invisibilizar su capacidad creadora.

La relación entre oralidad y escritura en el caso de las tomas de posesión se visualiza más claramente al compararse con las solicitudes y autos de mercedes de tierras y encomiendas, y los contratos de compraventa. Los enunciados de estos textos están conjugados en un tiempo presente: "suplica a vuestra señoría se sirva de hacer merced", "en real nombre 
le hago merced", "en efecto de la presente otorga que da, y vende realmente", sólo por mencionar algunos ejemplos. Son escritos cuya primera función era performativa, es decir, el texto era productor de una realidad que al mismo tiempo describía, y ese efecto era lo que, a su vez, habilitaba la futura instancia ritual de la toma de posesión.

Como mostramos a lo largo del trabajo, en las tomas de posesión muchas de las relaciones entre signos y referentes estaban lejos de ser arbitrarias. Cuando al tomar a un indio se toma de posesión de la totalidad de la encomienda, cuando al mover piedras de un lugar a otro se toma posesión del territorio o cuando al recibir la vara se toma posesión de un cargo estamos frente a relaciones metonímicas convertidas en "relaciones de participación" (Tambiah, 1996). La noción de señal da cuenta de esa perspectiva en tanto se entendía que esas señales participaban de su propio referente; creaban el mundo al cual referían.

Las fórmulas mágicas de los trobriandeses y la idea de un lenguaje que opera de forma práctica en el mundo social no están tan alejadas de algunos modos en que los protagonistas del mundo hispano colonial legitimaban sus derechos de posesión sobre tierras, encomiendas y cargos. Y tampoco tan distantes de los rituales de toma de posesión a los que actualmente podemos asistir o ver y escuchar por televisión. Si bien es claro que advertir la existencia de prácticas similares en diferentes sociedades no nos habilita a extrapolar los sentidos o funciones que se realizan en cada contexto, la exploración de un caso puede contribuir a reflexionar o problematizar otros recortes etnográficos. La creencia en el poder de la palabra y de las acciones rituales para producir ciertos efectos en la realidad es condición para lograr la eficacia que el ritual pretende. El análisis aquí desarrollado sugiere que en las tomas de posesión hispano coloniales esa creencia descansaba a su vez en la identificación que se producía entre la palabra y el objeto representado, o entre el ritual y el mundo simbolizado. La indagación en tomas de posesión que no resultaran eficaces, que fueran puestas en discusión o que debieran ser llevadas a cabo nuevamente podría contribuir a iluminar esa compleja relación no siempre arbitraria entre signos y referentes.

Hay múltiples formas en que los hombres organizan y orientan sus experiencias, y los rituales - por el tipo de operaciones simbólicas a las cuales apelan - permiten visualizar y explorar una de estas alternativas (Tambiah, 1996). La distinción entre ritual y escritura que nortea este trabajo en un punto termina por opacarse al mostrarnos que los textos son partícipes de esa misma lógica. Incluso, en el caso de las tomas de posesión vimos que los documentos y la acción de escribir eran elementos constitutivos del ritual, necesarios para conseguir su eficacia. Cuando en la introducción señalamos que tratamos las fuentes como instrumento y 
SILVINA SMIETNIANSKY. EL USO MOTIVADO DEL LENGUAJE: ESCRITURA Y ORALIDAD EN LOS RITUALES ...

como objeto de investigación podría pensarse que es, en parte, consecuencia de estas múltiples orientaciones sobre el mundo que las mismas comportan. En tanto buscamos reconstruir un ritual pasado, por un lado, ellas son tratadas en su dimensión referencial, son el medio de que disponemos para aproximarnos a aspectos de una realidad que ya no está presente. Por otro lado, en tanto las fuentes participaron de las mismas situaciones que constituyen el objeto de sus relatos y comportaron modos de construir ese mundo social al que queremos acceder, es también necesario incorporarlas al análisis en términos de su performatividad.

Buscando trascender las clásicas dicotomías pensar/vivir, acción/creencia, forma/ contenido, Tambiah apunta que las formas de comunicación a las que recurre el ritual son también producto de elecciones y definiciones provistas por la cultura. En ese sentido, la imbricación que los rituales muestran entre forma y contenido marca la necesidad de conjugar un análisis cultural y un enfoque formal. En sus palabras, "I hope to demonstrate that cultural considerations are integrally implicated in the form that ritual takes, and that a marriage of form and content is essential to ritual action's performance character and efficacy" (1985: 129, énfasis en original). Estas ideas subyacen al abordaje que efectuamos sobre la toma de posesión como ritual y también al tratamiento de dimos a las fuentes, y nos permiten tender un puente con trabajos más recientes que discuten las características e implicancias de una aproximación etnográfica a los documentos. Al reflexionar sobre el uso dado a los archivos coloniales, Stoler critica que los investigadores se han centrado en el contenido de informes y comisiones de gobierno mientras que raramente se han detenido a indagar su forma y contexto particulares. Para compensar esa mirada "a contrapelo", convoca una mirada guiada por la propia lógica de producción y circulación de esos documentos, y que repare en la "forma del archivo": "We need to read for its regularities, for its logic of recall, for its densities and distributions, for its consistencies of misinformation, omission, and mistake - along the archival grain" (Stoler, 2002: 100). En el estudio de la burocracia y las instituciones de gobierno actuales, desde la antropología también se avanza sobre estas ideas al marcar la necesidad de abordar los documentos como elementos constitutivos de la producción de conocimiento, relaciones, subjetividades, prácticas, afectividades, reglas burocráticas etc., destacando que, para ello, es preciso atender no sólo a su contenido informativo, sino también a su carácter estético, formal y material (Hull, 2012; Lowenkron y Ferreira, 2014).

$\mathrm{Al}$ acercarnos a la tarea del historiador, estas aproximaciones aportan a reflexionar sobre cómo, en cuanto antropólogos, definimos y ejercitamos la mirada etnográfica en situaciones en las que el diálogo con un otro está mediado por el registro escrito. Tal vez, así como reconocemos 
que la forma del ritual no es un mero canal de transmisión de mensajes sino parte del contenido cultural, una de las claves resida en profundizar la discusión sobre la idea del documento como un "medio" o una "fuente" y avanzar desde una mirada que contemple "el archivo como fuente" hacia otra noción, la del "archivo como sujeto" (Stoler, 2009).

No obstante, el hecho de que tratemos con archivos, documentos, papeles, en fin, con objetos, no debe hacernos olvidar que en realidad buscamos dialogar y aproximarnos a los modos de comprender el mundo de quienes produjeron, leyeron, manipularon o simplemente observaron esos escritos. Avanzar en un abordaje que contemple su función pragmática y que considere el contexto en que se utilizaron, se elaboraron y revistieron significado, y en el cual los sujetos les imprimieron intereses y motivaciones particulares, contribuye en esa dirección. La documentación de tipo institucional, como la que explora este trabajo, suele dejar poco margen para descubrir las huellas singulares de contextos y personas. La formalización de su estilo comprime una realidad que podemos suponer - como todas más flexible, contradictoria y confusa. Pero entonces nuevamente se impone la pregunta por cómo ese mundo, al tiempo que se inscribe en un registro escrito, también se construye.

\section{Notas}

${ }^{1}$ Este trabajo es resultado del proyecto de investigación posdoctoral que, con apoyo del cNpq, llevé a cabo en el marco del PPGAS del Departamento de Antropología de la Universidad de Brasilia entre 2013 y 2015. Una primera versión fue presentada en la 29ª Reunião Brasileira de Antropologia, Natal (RN), 3 al 6 de agosto de 2014. Agradezco a Mariza Peirano por su atenta lectura y valiosas sugerencias, y a los evaluadores anónimos de la Revista por sus pareceres.

${ }^{2}$ La institución de la encomienda implicaba la concesión de grupos de indios a los colonos españoles. Éstos tenían la obligación de evangelizarlos y cuidar de ellos y como contraprestación gozaban del derecho a percibir el tributo y el usufructo del trabajo indígena.

${ }^{3}$ Hasta 1776, momento en que fue creado el Virreinato del Río de la Plata, la gobernación del Tucumán integraba el Virreinato del Perú, cuya capital era Lima, y estaba bajo la órbita judicial y administrativa de la Audiencia de Charcas (actual Sucre). Situada en el actual territorio argentino (parte del centro y el noroeste), la jurisdicción comprendía las ciudades de Jujuy, Salta, La Rioja, Catamarca, Santiago del Estero, Tucumán y Córdoba. La residencia del gobernador y la sede del episcopado se establecieron en Santiago del Estero, y en el siglo XVIII se trasladaron a Salta y Córdoba, respectivamente.

${ }^{4}$ La condición de vecino constituía una distinción particular dentro del sector hispano-criollo, y suponía la posesión de una casa poblada en la ciudad, la jefatura de la familia y el consentimiento de sus pares vecinos. Además, era necesario contraer matrimonio con una mujer española, o con una mujer criolla en caso de ser extranjero.

5 Actas Capitulares de Córdoba. 1952. Libro x: 1650-1661. Archivo Municipal de Córdoba. p. 556. 
SILVINA SMIETNIANSKY. EL USO MOTIVADO DEL LENGUAJE: ESCRITURA Y ORALIDAD EN LOS RITUALES ...

${ }^{6}$ Actas Capitulares de Córdoba. 1952. Libro x: 1650-1661. Archivo Municipal de Córdoba. p. 567.

7 Archivo Histórico Nacional, Madrid. 1753-1792. Residencia de Juan Martínez de Tineo, gobernador de Tucumán. Consejos, 20375, expediente 1, Pieza 8, f. 402v.

${ }^{8}$ Archivo y Biblioteca Nacional de Bolivia (ABNB), Sucre. Expedientes Coloniales (EC) 1672-15. Expediente seguido por el señor fiscal sobre que se saque a un nuevo remate el oficio de Alcalde Provincial de la Ciudad de la Rioja en el Partido de Buenos Aires, por haber desamparo el que hizo Don Joseph Sanchez, de Loria; y a posesión hecha por este. f. $4 \mathrm{v}-5 \mathrm{r}$.

${ }^{9}$ Archivo de Tribunales de Jujuy (AтJ), Carpeta 29, orden 969. Sin título. F. 26r-26v.

${ }^{10}$ ATJ, Carpeta 29, orden 969, f. 26v.

${ }^{11}$ ATJ, Carpeta 29, orden 969, f. 28r.

${ }^{12} \mathrm{El}$ derecho romano, en lo que refiere a las cosas (res) del derecho privado, distingue entre las corporales - como un campo, un esclavo o dinero - y las incorporales o iura - un usufructo o una servidumbre, por ejemplo (Levaggi, 1982).

${ }^{13}$ En 1734 Bartolomé Domínguez tomó posesión de unas tierras que le habían sido legadas a su mujer en tanto viuda y heredera de Agustín de la Tijera (primer marido de la misma). El auto obrado por el alguacil testimonia que Domínguez "en señal de ella [de la posesión] se paseó por las dichas tierras e hizo otros actos de verdadera posesión y la aprendió quieta y pacíficamente sin contradicción de persona". ATJ, Carpeta 27, orden 848, 1734, s/f.

${ }^{14}$ Incluso, en términos jurídicos, el derecho romano postulaba que la posesión era una "representación viva de la propiedad", la demostración de poseer era parte del hecho de posesión (Levaggi, 1982).

${ }^{5}$ En la visita que el oidor Luján de Vargas realizó a los indios encomendados de la provincia del Tucumán en 1692-1694, frente a la pregunta de si éstos "tienen [...] tierras para sembrar", manifestaba que los encomenderos no habían señalado a los indios dichas porciones de tierras. Otra manera de referir esta falta era apuntar que los indios no tenían tierras señaladas. Al dirigirse a uno de lo encomenderos, le ordenó que "dentro del segundo día señale tierras a los dichos indios con agua para que puedan sustentar y tener su reducción más cómodamente” (Boixadós y Zanolli, 2003: 78).

${ }^{6}$ Los Villafañe constituyeron una de las familias más importantes de la élite riojana, que hacia comienzos del siglo xviII lograron monopolizar, junto con los Bazán, los puestos en el gobierno local. Lázaro de Villafañe fue el fundador de dicho linaje (Boixadós, 2004).

${ }^{7}$ Archivo General de Indias (AGI), Charcas, 102, N. 16, s/ f.

${ }^{8}$ AGI, Charcas, 102, N. 16, s/ f.

${ }^{9}$ AGI, Charcas, 102, N. 16, s/ f.

${ }^{20}$ AGI, Charcas, 102, N. 16, s/ f. 
SILVINA SMIETNIANSKY. EL USO MOTIVADO DEL LENGUAJE: ESCRITURA Y ORALIDAD EN LOS RITUALES ...

\section{Fuentes editadas}

Actas Capitulares de Córdoba. 1952. Libro x: 1650-1661. Archivo Municipal de Córdoba.

Boixadós, Roxana y ZanolLi, Carlos

2003 La visita de Luján de Vargas a las encomiendas de La Riojay Jujuy (1693-1694). Estudios preliminares y fuentes. Bernal, Universidad Nacional de Quilmes.

\section{Fuentes inéditas}

Archivo General de Indias (AGI), Sevilla. Charcas, 102, N. 16.

Archivo Histórico Nacional (AHN), Madrid. 1753-1792. Residencia de Juan Martínez de Tineo, gobernador de Tucumán. Consejos, 20375, expediente 1.

Archivo y Biblioteca Nacional de Bolivia (ABNB), Sucre. Expedientes Coloniales 1672-15. Expediente seguido por el señor fiscal sobre que se saque a un nuevo remate el oficio de Alcalde Provincial de la Ciudad de la Rioja en el Partido de Buenos Aires, por haber desamparo el que bizo Don Joseph Sanchez de Loria; y a posesión hecha por este.

Archivo de Tribunales de Jujuy (ATJ). Carpeta 29, orden 969. Sin título.

Archivo de Tribunales de Jujuy (ATJ). Carpeta 27, orden 848, 1734. Merced de zenta

\section{Referências bibliográficas}

AgÜERO, Alejandro

2007 "Las categorías básicas de la cultura jurisdiccional". In LoRente SariñEna, Marta (org.), De justicia de jueces a justicia de leyes. Hacia la España de 1870. Cuadernos de Derecho Judicial 6. Madrid, Consejo General del Poder Judicial, pp. 20-58

Austin, John L.

1975 [1955] How to Do Things with Words. Cambridge, Harvard University Press. 
SILVINA SMIETNIANSKY. EL USO MOTIVADO DEL LENGUAJE: ESCRITURA Y ORALIDAD EN LOS RITUALES ...

Barton, David e Papen, Uta

2010 "What is the Anthropology of Writing?". In (orgs.), The Anthropology of Writing: Understanding Textually Mediated Worlds. Londres, Continuum International Publishing Group, pp. 3-32

Bayle, Constantino 1952 Los cabildos seculares en la América española. Madrid, Sapiente S.A. Ediciones.

Beceiro Pita, Isabel

1994 “El escrito, la palabra y el gesto en las tomas de posesión señoriales". Studia Historica. Historia Medieval. España, vol. 12: 53-82.

BoIXADÓs, Roxana

1994 "Fundaciones de ciudades como rituales. Análisis de tres casos en el contexto de la conquista del Tucumán colonial”. Anuario Antropológico, Brasília, vol. 92: 145178.

2004 'Asuntos de familia, cuestiones de poder: la 'concordia' en el Cabildo de La Rioja, Gobernación del Tucumán, 1708”. Colonial Latin American Historical Review, Albuquerque, 13 (2): 147-171.

BRIDIKHINA, Eugenia

2007 Theatrum mundi. Entramados del poder en Charcas colonial. Bolivia, Instituto Francés de Estudios Andinos / Plural Ediciones.

CAÑeque, Alejandro 2004 The King's Living Image: The Culture and Politics of Viceregal Power in Colonial Mexico. Nova York, Routledge.

ELLIOT, John H.

1990 "La conquista española y las colonias de América". In Bethell, L. (org.), Historia de América Latina 1. América Latina Colonial: La América Precolombina y la conquista. Barcelona, Editorial Crítica, pp. 125-169 
FRAENKEL, Béatrice

2010 "Writing Acts: When Writing Is Doing". In Barton, David e Papen, Uta (orgs.), The Anthropology of Writing: Understanding Textually Mediated Worlds. Londres, Continuum International Publishing Group, pp. 33-43

GiBson, Charles

1990 "Las sociedades indias bajo el dominio español". In Bethell, L. (org.), Historia de América Latina 1. América Latina Colonial: La América Precolombina y la conquista. Barcelona, Editorial Crítica, pp. 125-169

Hull, Matthew

2012 "Documents and Bureaucracy". Annual Review of Anthropology, 41: 251-267.

LE GoFf, Jacques

1983 [1978] Tiempo, trabajo y cultura en el Occidente medieval. Madrid, Taurus Ediciones.

LeVaggi, Abelardo

1982 Historia del derecho, de las obligaciones, contratos y cosas. Buenos Aires, Editorial Perrot.

Lowenkron, Laura e Ferreira, Leticia

2014 "Anthropological Perspectives on Documents. Ethnographic Dialogues on the Trail of Police Papers". Vibrant - Virtual Brazilian Anthropology, v. 11, n. 2: 75-111.

MaLinowski, Bronislaw

1930 “The problem of meaning”. In Ogden, C.K. e Richards, I.A. (orgs.), The Meaning of Meaning. Londres, Kegan Paul.

MARIluz Urquijo, José María

1978 El régimen de la tierra en el derecho indiano. Buenos Aires, Editorial Perrot.

Mauss, Marcel

2009 Ensayo sobre el don. Forma y función del intercambio en las sociedades arcaicas. Buenos Aires, Katz Editores. 
SILVINA SMIETNIANSKY. EL USO MOTIVADO DEL LENGUAJE: ESCRITURA Y ORALIDAD EN LOS RITUALES ...

MÖRner, Magnus

1990 "Economía rural y sociedad colonial en las posesiones españolas de Sudamérica". In Bethell, L. (org.), Historia de América Latina 3. América Latina Colonial: economía. Barcelona, Editorial Crítica, pp. 122-147.

Ortemberg, Pablo

2014 Rituales del poder en Lima (1735-1828). De la monarquía a la república. Lima, Fondo Editorial PuCP.

Osorio, Alejandra

2004 “The King in Lima: Simulacra, Ritual, and Rule in Seventeenth-Century Peru”. Hispanic American Historical Review, Durham, Duke University Press, 84 (3).

Peirano, Mariza

2001 “A análise antropológica de rituais". In Peirano, M. (org.), O dito e o feito. Ensaios de antropologia dos rituais. Rio de Janeiro, Relume Dumará, pp. 17-40.

PeIrce, Charles

1955 "How To Make Our Ideas Clear", "Logic as Semiotic: The Theory of Signs", "The Principles of Phenomenology". In Buchler, J. (org.), Philosophical Writings of Peirce. Nova York, Dover Publications, pp. 23-41, 98-119.

SEed, Patricia

1998 [1995] Ceremonies of Possession in Europe's Conquest of the New Word, 1492-1640. Cambridge, Cambridge University Press.

SiLVERSTEIn, Michael

1997 [1963] "Language as Part of Culture". In Sol, T. e Freeman, L. G. (orgs.), Horizons of Anthropology (2 edição). Chicago, Aldine Publishing Company, pp. 119131.

STOLER, Ann Laura

2002 "Colonial Archives and the Arts of Governance". Archival Science, 2: 87-109. 
SILVINA SMIETNIANSKY. EL USO MOTIVADO DEL LENGUAJE: ESCRITURA Y ORALIDAD EN LOS RITUALES ...

TAMBiaH, Stanley

1985 Culture, Thought and Social Action. Cambridge, Harvard University Press.

1996 "Relations of Analogy and Identity. Toward Multiple Orientations to the World". In Olson, D. e Torrance, N. (ogss.), Modes of Thought. Explorations in Culture and Cognition. Cambridge, Cambridge University Press.

\title{
The motivated use of language: writing and orality in the rituals of toma de posesión. The case of colonial Latin America
}

\begin{abstract}
The act of toma de posesion defines an instance of transformation in which verbal statements, rituals actions and written texts are combined to produce and legitimate the concession of a public charge or the transfer of a property. It establishes by these means a new status for the subject involved. This article proposes an ethnographic approach to the study of the performative dimension of language and the uses of orality and writing, for understanding where lies the efficacy of such practice. By exploring documentation elaborated by Latin America colonial government institutions, three different cases of tomas de posesion are examined: a possession of land, a public charge and an encomienda de indios. The approach to this problem includes a reflection about the capacity of written materials to describe and to create the social world we intend to understand.
\end{abstract}

KEYWORDS: Toma de posesión, Languaje, Writing, Ritual, Colonial Latin America.

Recebido em julho de 2015. Aceito em junho de 2016. 